Thornicroft G, Bebbington P. Deinstitutionalisation: from hospital closure to service development. Br F Psychiatry 1989;155:739-5

2 Team for the Assessment of Psychiatric Services (TAPS). Better out than in? Report of the 5th annual TAPS conference. London: North East Thames Repon of the Sth annual TAPS

3 Clarke A. Are readmissions avoidable? BM7 1990;301:1136-8.

4 Chambers M. Clarke A. Measuring readmission rates. BMF 1990;301:1134-6.

5 Milne R, Clarke A. Can readmissions be used as an outcome indicator? $B M \gamma$ 1990;301:1139-40.

6 Dayson D, Gooch C, Thornicroft G. The TAPS project. 16: Difficult to place, long term psychiatric patients: risk factors for failure to resettle long stay patients in community facilities. BMF 1992;305:993-5.

7 Wykes T, Sturt E. The measurement of social behaviour in psychiatric patients: an assessment of the reliability and validity of the SBS schedulc. Br F Psychiatry 1986;148:1-11.

8 Wing J, Cooper J, Sartorius N. The measurement and classification of psychiatric symptoms. Cambridge: Cambridge University Press, 1974.

9 Blumenthal S, Bell V, Neumann N, Schuettler R, Vogel R. Die Wiedereinweisung erthospitalisierter Patienten? Verlauf and praediktive Wiedereinweisung erthospitalisierter Patienten? Verlat

10 Geller J, Fisher W, With-Cauchon J, Simon L. Second-generation deinstitutionalisation, II: the impact of 'Brewster $v$. Dukakis' on correlates deinstitutionalisation, It: the impact of 'Brewster v. Dukakis' on corre

11 Setze P, Bond G. Psychiatric recidivism in a psychosocial rehabilitation setze P, Bond G. Psychiatric recidivism in a psychosocial rehabiliting: a survival analysis. Hosp Commmunty Psychiatry 1985;36:521-4.
setting:

12 Pokorny A, Kaplan H, Lorimor R. Effects of diagnosis and treatment histor on relapse of psychiatric patients. Am f Psychiarry 1983;140:1598-601.

13 Jones $\mathrm{K}$, Robinson $\mathrm{M}$, Golightly $\mathrm{M}$. Long-term patients in the community Brf Psychiaty 1986;149:537-40.

14 Avison W, Speechley K. The discharged psychiatric patient: a review of social, social-psychobiological and psychiatric correlates of outcome. Am f Psychiatry 1987;144:10-8.
15 Colenda C, Hmer R. First admission young adult patients to a state hospital: relative risk for rapid readmission. Psychiatr Q 1989;60:227-36.

16 Wan T, Ozcan Y. Determinants of psychiatric rehospitalisation: a social area analysis. Community Ment Health f 1991;27:3-16.

17 Zilber N, Popper M, Lerner Y Patterns and correlates of psychiatric hospitalisation in a nationwide sample. II Correlates of psychiatric hospitalization and length of stay out of hospital. Soc Psychiatry Psychiatr Epidemiol zation and length

18 Kastrup M. Who became revolving door patients? Acta Psychiatr Scand $1987 ; 76: 80-8$

19 Lewis T, Joyce $P$. The new revolving door patients: results from a national cohort of first admissions. Acta Psychiatr Scand 1990;82:130-5.

20 Okin R, Pearsall D, Athearn T. Predictions about new-long stay patient: were they valid? Am F Psychiatry 1990;147:1596-601

21 Lerner Y, Popper M, Zilber M. Patterns and correlates of psychiatric hospitalisation in a nationwide sample. Soc Psychiatry Psychiatr Epidemiol 1989;24:121-6.

22 Drake $R$, Wallach $M$, Hoffman J. Housing instability and homelessness among aftercare patients of an urban State hospital. Hosp Community Psychiatr. 1989:40:46-51.

23 Beiser M, Shore J, Peters R, Tatum E. Does community care for the mentally ill make a difference? A tale of two cities. Am $\mathcal{F}$ Psychiatry 1985;142:1047-52.

24 Haefner $\mathrm{H}$, van der Heiden $W$. The evaluation of mental health care systems. Brf Psychiatry 1989;155:12-7.

25 Kastrup .M. The use of a psychiatric register in predicting the outcome 'revolving door patient'. Acta Psychiatr Scand 1987;76:552-60.

26 Fernando M, Velamoor V, Cooper A, Cernovsky Z. Some factors relating to satisfactory post-discharge community maintenance of chronic psychotic patients. Can F Psychiatry 1990;35:71-3.

(Accepted 1 September 1992)

\section{Elder abuse in Britain}

\section{Jim Ogg, Gerry Bennett}

\section{Department of Health Care of the Elderly, Royal} London Trust, London E1 4DG

Jim Ogg, research and development officer Gerry Bennett, consultant physician in geriatric medicine

Correspondence to: Mr Ogg.

BMF 1992;305:998-9
Abuse of elderly people at home by family members or close relatives is currently attracting attention from social and health care practitioners. ${ }^{1-3}$ However, its prevalence remains unknown. In conjunction with the Office of Population Censuses and Surveys omnibus survey team we devised a series of questions, based on American and Canadian techniques for researching elder abuse, asking older people about abuse by family members or close relatives. ${ }^{+5}$ The omnibus survey is a nationally representative sample of about 2000 adults throughout Britain interviewed over two weeks; 500 600 of the adults would be aged 60 or over. Elderly people in institutions and those who were too ill or disabled to participate were not included.

\section{Subjects, methods, and results}

Adults aged 60 years and over were asked whether a close family member or relative had recently frightened them by shouting, insulting, or speaking roughly (verbal abuse); pushed, slapped, shoved, or been physically rough with them in any other way (physical abuse); or taken money or property from them without their consent (financial abuse). In addition, all adults who were in regular contact with people of pensionable age were asked whether they had recently found themselves shouting at, insulting, or speaking roughly to them or pushing, slapping, shoving, or being rough with them in any other way.

In the omnibus survey of May 1992, 2130 interviews were obtained from 2681 selected addresses $(79 \%)$. The table shows the responses of the people who answered questions on elder abuse.

The achieved sample is subject to sampling errors arising from the weighting procedures, and these errors add to the observed variance of the sample. Sampling errors would tend to make the confidence intervals wider, although previous Omnibus surveys have found this effect to be negligible. We estimated the number of abused elderly people in the general population by calculating two standard errors around the sample proportion (using the conventional standard error of a proportion formula) based on the age distribution of people 60 and over in the 1981 census For adults reporting abuse to an elderly person estimations in the general population were calculated by using the conventional standard error of a proportion of the total sample - that is, 2130 respondentsbased on the registrar general's population estimate of people in Britain aged 16 years and over in 1990.

\section{Comment}

We used wide behavioural definitions of abuse to determine whether respondents were willing to divulge personal and intimate information and to obtain a broad schema of the prevalence of elder abuse. We realise that some of the behaviour reported was probably not "abusive" in terms of severity and intensity. Nevertheless, the results are the first systematic British evidence of elder abuse in the domestic setting. The survey excluded the most frail and vulnerable elderly people, who are most at risk of abuse. ${ }^{2}$ Our findings should therefore not be taken in isolation from other attempts to systematically identify elder abuse. Anecdotal evidence suggests that rates of abuse in elderly people known to social and health care practitioners are higher than rates in the general population.

Analysis of abuse of elderly people and adults reporting abuse to elders by age with estimates for total British population

\begin{tabular}{|c|c|c|c|c|c|c|c|c|c|c|c|}
\hline \multirow[b]{2}{*}{ Type of abuse } & \multicolumn{3}{|c|}{ No $(\%)$ of elderly people abused } & \multirow{2}{*}{$\begin{array}{l}95 \% \text { Confidence interval } \\
\text { for British population } \\
(\times 1000)^{\star}\end{array}$} & \multicolumn{6}{|c|}{ No $(\%)$ of adults reporting abuse to elderly people } & \multirow{2}{*}{$\begin{array}{l}95 \% \text { Confidence interval } \\
\text { for British population } \\
(\times 1000)^{\star}\end{array}$} \\
\hline & $\begin{array}{c}60-64 \\
(n=150)\end{array}$ & $\begin{array}{c}65-74 \\
(n=266)\end{array}$ & $\begin{array}{c}\geqslant 74 \\
(n=173)\end{array}$ & & $\begin{array}{c}16-24 \\
(n=156)\end{array}$ & $\begin{array}{c}25-44 \\
(n=486)\end{array}$ & $\begin{array}{c}45-54 \\
(n=233)\end{array}$ & $\begin{array}{c}55-64 \\
(n=188)\end{array}$ & $\begin{array}{c}65-74 \\
(\mathrm{n}=182)\end{array}$ & $\begin{array}{c}\geqslant 74 \\
(\mathrm{n}=110)\end{array}$ & \\
\hline Verbal & $11(7)$ & $16(6)$ & $6(3)$ & 561 to 1123 & $10(6)$ & $48(10)$ & $26(11)$ & $29(15)$ & $7(4)$ & $6(5)$ & 2411 to 3305 \\
\hline Physical & $5(3)$ & $4(2)$ & $1(1)$ & 94 to 505 & $7(4)$ & $4(1)$ & $1(0.4)$ & $1(1)$ & & & 134 to 402 \\
\hline Financial & $5(3)$ & $2(1)$ & $2(1)$ & 94 to 505 & & & & & & & \\
\hline
\end{tabular}

*See results section for derivation. 
American studies suggest that appropriate measures of abusive behaviours can be achieved. However, pilot studies with in depth interviews at our hospital found several methodological problems. These included the obtaining of informed consent to participate in research on family violence, access to potential respondents, and ethical dilemmas about procedure if abuse is uncovered during research. Further British research will therefore need to address these problems before large scale studies of elder abuse are conducted.
Population Censuses and Surveys omnibus survey team in undertaking this survey.

1 Bennett G. Action on elder abuse in the 1990s: new definitions will help. Geriatric Medicine 1990;April:53-4.

2 Homer AC, Gilleard C. Abuse of elderly people by their carers. BMY 1990;301:1359-62.

3 Social Services Inspectorate. Confronting elder abuse. London: HMSO, 1992.

4 Pillemer K, Finkelhor D. The prevalence of elder abuse: a random sample survey. Gerontologist 1988;28:51-7.

5 Podnieks E, Pillemer K. National survey on the abuse of the elderly in Canada. Ottawa: Ryerson Polvtechnical Institute, 1989.

We acknowledge the support of Channel 4 and the Office of (Accepted 6) (Otober 1992)

\title{
Steroids in advanced cancer: survey of current practice
}

\author{
P R Needham, A G Daley, R F Lennard
}

\section{St Joseph's Hospice, London E8 4SA P R Needham, senior house officer \\ A G Daley, registrar}

\section{Department of Clinical} Pharmacology and

Therapeutics, The London London E1 2AD

R F Lennard, Macmillan senior lecturer in palliative medicine

Correspondence to: Dr Patricia Needham, c/o Department of Clinical Pharmacology and Therapeutics, The London Hospital Medical College, London E1 2AD.

BMF 1992;305:999 Hospital Medical College,

Steroids are commonly prescribed for patients with malignant disease.' At St Joseph's Hospice three patients were admitted in one month with severe side effects of steroids in whom the rationale for using steroids was not clear. This prompted us to look at steroid use in a series of patients admitted to the hospice.

\section{Subjects, method, and results}

In 100 patients admitted consecutively with advanced cancer, information regarding steroid use and usefulness was sought from the patient, the patient's family, any accompanying documentation, and doctors outside the hospice involved in the patient's care. A total of 33 of the patients were taking steroids at the time of admission. Most had been taking them for more than one month. Reasons for steroids and durations of use are shown in the table.

Ten patients were admitted from the hospice homecare team with detailed notes. Of the 23 patients admitted from general practitioners or hospital doctors, only two had accompanying documentation giving indications for and dose of steroids. In two letters steroids were not mentioned. Three patients arrived with no documentation at all. After extensive telephoning we were unable to establish the reason for steroid use in four patients.

In most cases the response to steroids did not seem to have been monitored. Of the 28 patients who could answer questions, only eight felt that steroids had been beneficial, nine were uncertain, and 11 did not perceive

Reason for and duration of steroid use

\begin{tabular}{|c|c|c|c|c|c|c|}
\hline \multirow[b]{2}{*}{ Reason for use } & \multicolumn{5}{|c|}{ Duration of use (weeks) } & \multirow[b]{2}{*}{ Total } \\
\hline & $<1$ & $1-4$ & $5-52$ & $>52$ & Unknown & \\
\hline Anorexia/weakness & 2 & 3 & 2 & 1 & 1 & 9 \\
\hline Anorexia/weakness and pain & & & 2 & & & 2 \\
\hline Anorexia/weakness and hepatomegaly & & 1 & & & & 1 \\
\hline Anorexia/weakness and vomiting & & & 1 & & & 1 \\
\hline Raised intracranial pressure & & 1 & 5 & & & 6 \\
\hline Painful neuropathy & & & 1 & & & 1 \\
\hline Facial palsy and radiotherapy & & & 1 & & & 1 \\
\hline Chronic obstructive airways disease & & & & 1 & & 1 \\
\hline Pain & 1 & & 1 & & & 2 \\
\hline Spinal cord compression & 1 & & & & & 1 \\
\hline Intestinal obstruction & & & 1 & & & 1 \\
\hline Lymphoma & & 1 & & & & 1 \\
\hline Eczema & & & 1 & & & 1 \\
\hline Part of chemotherapy regimen & & 1 & & & & 1 \\
\hline Unknown & 1 & 1 & & & 2 & 4 \\
\hline Total & 5 & 8 & 15 & 2 & 3 & 33 \\
\hline
\end{tabular}

any benefit. Five of these 11 had been taking them for more than one month. Of nine patients taking steroids solely for anorexia and weakness, only one had perceived any improvement.

Nine patients had steroid cards. Only eight of the 28 patients who could answer questions knew of the dangers of stopping steroids suddenly. Fifteen did not know why they were taking steroids, and 16 did not know whether the dose was to be reduced or continued. Six patients had distressing side effects attributable to prolonged steroid use. Four had a moon face, one a debilitating proximal myopathy, and one severe osteoporosis (she had been taking $30 \mathrm{mg}$ prednisolone for two years without clear benefit to her anorexia and weakness).

\section{Comment}

Steroids can be prescribed for a number of reasons in advanced malignancy, 12 the best known being their stimulant effect in anorexia and weakness ${ }^{34}$ and to reduce oedema around cerebral tumours. ${ }^{5}$ They confer clear benefits in $40 \%$ of patients overall' but, particularly when used for more than a month, they can seriously impair quality of life as well as adding to the drug load in patients often already subject to polypharmacy. It is therefore of concern that steroid benefits are not routinely monitored, that patients are not aware of the risks, and that communication between doctors about steroid prescription is poor.

There is no universally accepted dose or monitoring regimen for steroids in advanced cancer, but a review of the literature suggests that typical starting doses would be $4 \mathrm{mg}$ of dexamethasone daily in anorexia and weakness and $16 \mathrm{mg}$ daily for the reduction of cerebral oedema or for spinal cord compression. Results can be assessed after one week, when the drug can be stopped if there has been no therapeutic response. If there is improvement in symptoms it seems sensible to reduce to the minimum dose which maintains benefit. ${ }^{5}$ If steroids are continued it should be the responsibility of the prescribing doctor to ensure that the patient or family is aware of the dangers of stopping steroids suddenly and that response and adverse effects are clearly recorded.

We thank all the staff at St Joseph's Hospice who assisted in collecting data for this survey, and the Cancer Relief Macmillan Fund for their support of RFL.

1 Hanks G, Trueman T, Twycross R. Corticosteroids in terminal cancer. Postgrad Med f 1983;59:702-6.

2 Herxheimer A, ed. Corticosteroids in terminal cancer. Drig Ther Bull 1974;16:63-4.

3 Moertel C, Schutt A, Reitemeier R, Hahn R. Corticosteroid therapy of preterminal gastrointestinal cancer. Cancer 1974;33:1607-9.

4 Willcox J, Corr J, Shaw J, Richardson M, Calman K, Drennan M. Prednisolone as an appetite stimulant in patients with cancer. BMJ 1984;288:27.

5 Weissman D. Glucocorticoid treatment for brain metastases and epidural spinal cord compression: a review. 3 Clin Oncol 1988;6:543-51.

(Accepted 3 September 1992) 